\title{
CHInese Medicine NeuroAiD Efficacy on Stroke Recovery - Extension Study (CHIMES-E): A Multicenter Study of Long-Term Efficacy
}

\author{
Narayanaswamy Venketasubramanian ${ }^{a}$ Sherry H. Young ${ }^{b}$ San San Tay ${ }^{b}$ \\ Thirugnanam Umapathic $^{c}$ Annabelle Y. Lao ${ }^{d}$ Herminigildo H. Gan ${ }^{e}$ \\ Alejandro C. Baroque II ${ }^{f}$ Jose C. Navarro ${ }^{f}$ Hui Meng Chang ${ }^{g}$ \\ Joel M. Advincula ${ }^{\mathrm{h}}$ Sombat Muengtaweepongsa ${ }^{\mathrm{i}}$ Bernard P.L. Chan ${ }^{\mathrm{j}}$
}

Carlos L. Chuak Nirmala Wijekoon' H. Asita de Silval John Harold B. Hiyadan ${ }^{m}$

Nijasri C. Suwanwela ${ }^{n}$ K.S. Lawrence Wong ${ }^{\circ}$ Niphon Poungvarin $^{p}$ Gaik Bee Eow ${ }^{q}$

Chun Fan Leer Christopher L.H. Chen ${ }^{s}$ for the CHIMES-E Study Investigators

${ }^{a}$ Raffles Neuroscience Centre, Raffles Hospital, Singapore, ${ }^{b}$ Changi General Hospital, Singapore, and ${ }^{c}$ National Neuroscience Institute - Tan Tock Seng Campus, Singapore, Singapore; d Davao Medical School Foundation Hospital, Room 415, Medical Arts Building, San Pedro Hospital, Davao City, e Jose Reyes Memorial Medical Center, San Lazaro Compound, Sta. Cruz, Manila, and f University of Santo Tomas Hospital, Manila, Philippines; ${ }^{9}$ National Neuroscience

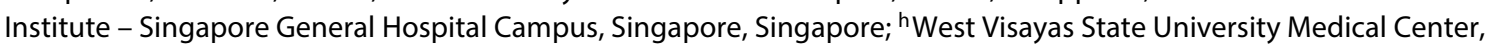
Lapaz, Iloilo City, Philippines; 'Thammasat University, Pathum Thani, Thailand; 'National University Hospital, National

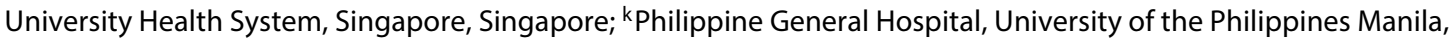
Manila, Philippines; 'University of Kelaniya, Ragama, Sri Lanka; 'maguio General Hospital and Medical Center, Baguio City, Philippines; ${ }^{\mathrm{n}}$ Chulalongkorn University, Pathunwan, Bangkok, Thailand; ${ }^{\circ}$ Chinese University of Hong Kong, Prince of Wales Hospital, Shatin, New Territories, Hong Kong; ${ }^{p}$ Siriraj Hospital, Bangkoknoi, Bangkok, Thailand; ${ }^{9}$ Penang Hospital, Jalan Residensi, 10990, Georgetown, Penang, Malaysia; 'rSingapore Clinical Research Institute, Singapore, and ${ }^{\mathrm{s}} \mathrm{National}$ University of Singapore, Clinical Research Centre, Singapore, Singapore

\section{Key Words}

Acute stroke - Traditional Chinese medicine - Stroke recovery · MLC601 · NeuroAiD · Clinical trial · Long-term outcome

\section{Abstract \\ Background: The CHInese Medicine NeuroAiD Efficacy on Stroke recovery (CHIMES) study was an international ran- domized double-blind placebo-controlled trial of MLC601 (NeuroAiD) in subjects with cerebral infarction of intermedi-}

ate severity within 72 h. CHIMES-E (Extension) aimed at evaluating the effects of the initial 3-month treatment with MLC601 on long-term outcome for up to 2 years. Methods: All subjects randomized in CHIMES were eligible for CHIMESE. Inclusion criteria for CHIMES were age $\geq 18$, baseline National Institute of Health Stroke Scale of 6-14, and pre-stroke modified Rankin Scale (mRS) $\leq 1$. Initial CHIMES treatment allocation blinding was maintained, although no further study treatment was provided in CHIMES-E. Subjects received standard care and rehabilitation as prescribed by the treating physician. mRS, Barthel Index (BI), and occurrence of

\begin{tabular}{ll}
\hline KARGER 125:3 & $\begin{array}{l}\text { (2015 S. Karger AG, Basel } \\
1015-9770 / 15 / 0396-0309 \$ 39.50 / 0 \quad \text { Karger }\end{array}$ \\
$\begin{array}{l}\text { E-Mail karger@karger.com } \\
\text { www.karger.com/ced }\end{array}$ & $\begin{array}{l}\text { This is an Open Access article licensed under the terms of the } \\
\text { Creative Commons Attribution-NonCommercial 3.0 Un- } \\
\text { ported license (CC BY-NC) (www.karger.com/OA-license), } \\
\text { applicable to the online version of the article only. Distribu- } \\
\text { tion permitted for non-commercial purposes only. }\end{array}$
\end{tabular}

Narayanaswamy Venketasubramanian

Raffles Neuroscience Centre, \#02-00 Raffles Hospital

585 North Bridge Road

Singapore 188770 (Singapore)

E-Mail drnvramani@gmail.com 
medical events were ascertained at months $6,12,18$, and 24 . The primary outcome was $\mathrm{mRS}$ at 24 months. Secondary outcomes were $\mathrm{mRS}$ and $\mathrm{BI}$ at other time points. Results: CHIMES-E included 880 subjects (mean age $61.8 \pm 11.3 ; 36 \%$ women). Adjusted OR for mRS ordinal analysis was 1.08 ( $95 \%$ $\mathrm{Cl} 0.85-1.37, \mathrm{p}=0.543$ ) and $\mathrm{mRS}$ dichotomy $\leq 1$ was 1.29 $(95 \% \mathrm{Cl} 0.96-1.74, \mathrm{p}=0.093)$ at 24 months. However, the treatment effect was significantly in favor of MLC601 for $\mathrm{mRS}$ dichotomy $\leq 1$ at 6 months (OR 1.49, 95\% Cl 1.11-2.01, p = $0.008), 12$ months (OR $1.41,95 \% \mathrm{Cl} 1.05-1.90, \mathrm{p}=0.023)$, and 18 months (OR 1.36, 95\% Cl 1.01-1.83, $\mathrm{p}=0.045$ ), and for $\mathrm{BI}$ dichotomy $\geq 95$ at 6 months (OR 1.55, 95\% Cl 1.14-2.10, $p=$ 0.005 ) but not at other time points. Subgroup analyses showed no treatment heterogeneity. Rates of death and occurrence of vascular and other medical events were similar between groups. Conclusions: While the benefits of a 3-month treatment with MLC601 did not reach statistical significance for the primary endpoint at 2 years, the odds of functional independence defined as $\mathrm{mRS} \leq 1$ was significantly increased at 6 months and persisted up to 18 months after a stroke.

(c) 2015 S. Karger AG, Basel

\section{Introduction}

Stroke is a major cause of death and disability with only a limited number of treatment options to improve functional outcome after stroke, including thrombolytic therapy, early use of aspirin, decompression craniectomy for malignant infarcts, stroke unit care, and constraintinduced movement therapy [1]. Strategies using neuroprotectants have failed in many clinical trials [2]. As many still remain disabled even after rehabilitation, stroke survivors have often turned to alternative and complementary therapies [3], most of which are of unproven value or have not been subjected to rigorous evaluation in wellconducted clinical trials.

MLC601 (NeuroAiD ${ }^{\mathrm{TM}}$ ), a natural product that combines herbal extracts and non-herbal components in the capsule form, demonstrated both neuroprotective and neurorestorative properties in preclinical models of focal and global ischemia [4-6]. Clinical studies, which assessed the benefit and safety of MLC601 in non-acute stroke patients using different clinical outcomes [7-16], have been published.

More recently, MLC601 was evaluated in the CHInese Medicine NeuroAiD Efficacy on Stroke recovery (CHIMES) study, a large international, multicenter, randomized, double-blind, placebo-controlled clinical trial, which showed a statistically nonsignificant effect of MLC601 at 3 months among subjects with cerebral infarction in the preceding $72 \mathrm{~h}$ (ClinicalTrials.gov: NCT00554723) [17-19]. It was among the first to investigate the use of a product from natural substances that reduced the disability after an acute stroke in a rigorous manner to achieve a balance between 'uncritical enthusiasm' and 'uninformed skepticism'.

CHIMES-E is a planned extension study that assessed outcomes over the 21 months after the final CHIMES study assessment was made. The objective was to test the hypothesis that MLC601 (NeuroAiD ${ }^{\mathrm{TM}}$ ), given over the initial 3 months after a stroke, is superior to placebo in improving the functional outcome for up to 2 years among subjects with cerebral infarction of intermediate severity.

\section{Methods}

Study Design and Participants

The trial protocol was previously published [20]. Briefly, all subjects randomized to either MCL601 or placebo in CHIMES were eligible for inclusion in CHIMES-E: aged 18 or older who had an ischemic stroke of intermediate severity defined as National Institutes of Health Stroke Scale (NIHSS) of 6-14 in the preceding $72 \mathrm{~h}$ with neuroimaging findings compatible with cerebral infarction and a pre-stroke modified Rankin Scale $(m R S) \leq 1$. Subjects were excluded if they had withdrawn consent from all participation and follow-up in CHIMES. This study was approved by the respective institutional review board of study sites.

\section{Randomization, Treatment and Blinding}

Subjects were randomly assigned in the CHIMES Study to receive a 3-month course of either MLC601 or placebo at a dose of 4 capsules 3 times daily. MLC601 and matching placebo were provided by Moleac (Singapore). Each 400 mg MLC601 capsule contained 9 herbal components (extracts derived from raw herbs consisting of Radix astragali, Radix salvia mitorrhizae, Radix paeoniae rubra, Rhizoma chuanxiong, Radix angelicae sinensis, Carthamus tinctorius, Prunus persica, Radix polygalae and Rhizoma acoritatarinowii) and 5 non-herbal components (Hirudo, Eupolyphaga seu steleophaga, Calculus bovis artifactus, Buthus martensii and Cornu saigaetataricae). Placebo included 4 constituents (barley, dried ripe fruit, noodle fish and citric acid) known to have no active effect but gave a similar appearance, smell, and taste as the active treatment $[17,18]$. To avoid center and processof-care effects, subjects were entered into the trial using randomized blocks of 4 and 6 (stratified by center) based on a 1:1 treatment allocation. Blinding of the subjects, their caregivers, investigators, study staff, sponsor, and study project coordinators to treatment allocation was maintained into the CHIMES-E study phase.

Throughout the CHIMES and CHIMES-E studies, all subjects were allowed to receive standard stroke care, including antiplatelet therapy, control of vascular risk factors, and appropriate rehabili- 


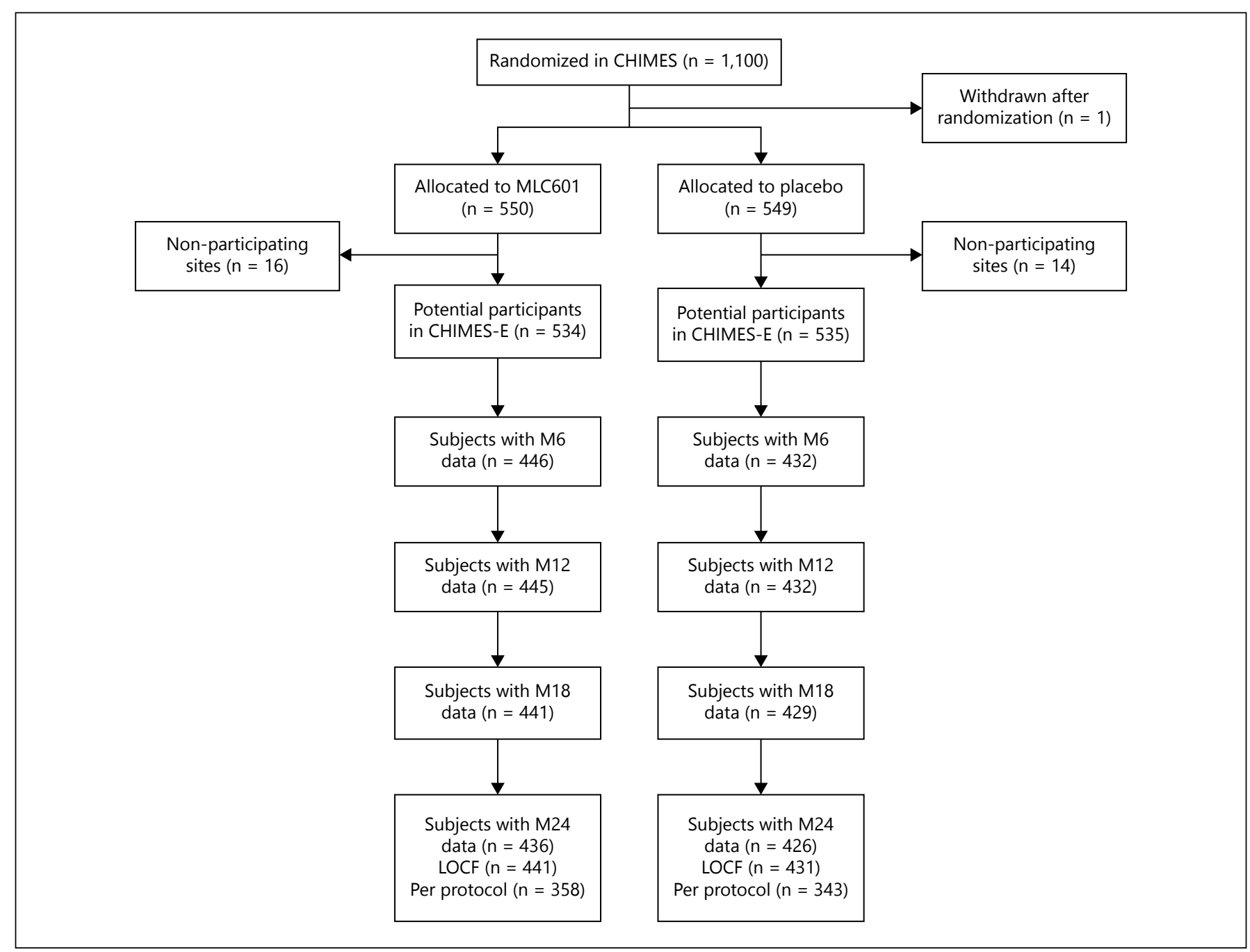

Fig. 1. Flow diagram of patients in CHIMES to the CHIMES-E Study. $M=$ Month; LOCF = last observation carried forward.

tation as prescribed by the treating physician. We have previously demonstrated that post-stroke use of concomitant secondary prevention treatments and rehabilitation in CHIMES were high and similar between the two treatment groups [19].

\section{Study Procedures}

Eligible subjects were contacted by telephone. After explaining the nature of the study using a standardized telephone script, verbal consent was obtained prior to performing the assessments that were carried out at month 6 ( \pm 1 month), month 12 ( \pm 1 month), month 18 ( \pm 1 month) and month 24 ( \pm 1 month).

Assessments were performed using a questionnaire. Data collected included mRS, Barthel Index (BI), self-report of having received rehabilitation, self-report of having received traditional Chinese medicine (TCM), self-report of having suffered a new vascular event (e.g. stroke, myocardial infarction), self-report of developing other significant illnesses, and occurrence of death and its cause.

CHIMES-E - Long-Term Efficacy of MLC601 in Stroke

\section{Power Calculation}

We assumed that $35 \%$ of moderately severe stroke patients would be dead (mRS 6) and 25\% would be dependent, distributed among mRS $2-5$, at 2 years [21-23]. We expected an overall $30 \%$ dropout rate after 2 years follow-up of the 1,100 patients recruited into CHIMES. Having mRS data available in 770 subjects at year 2 would have a power of $89 \%$ with two-sided type I error of $5 \%$ in detecting a cumulative odds ratio (OR) of 1.5 for the MLC601 group. Even with a sample size of 606 , we could ensure at least $80 \%$ power. Furthermore, a sample size of 816 would provide $80 \%$ power with $5 \%$ type 1 error in detecting a $10 \%$ increase in the proportion of subjects attaining $\mathrm{mRS} \leq 1$ in the treated group compared to $40 \%$ in the placebo group.

\section{Study Endpoints and Efficacy Analyses}

Efficacy analyses were based on the intention-to-treat principle. The primary endpoint was mRS at month 24 . The difference in distribution of subjects within each range of $\mathrm{mRS}$ between pla- 
Table 1. Baseline characteristics of CHIMES [18] and CHIMES-E cohorts

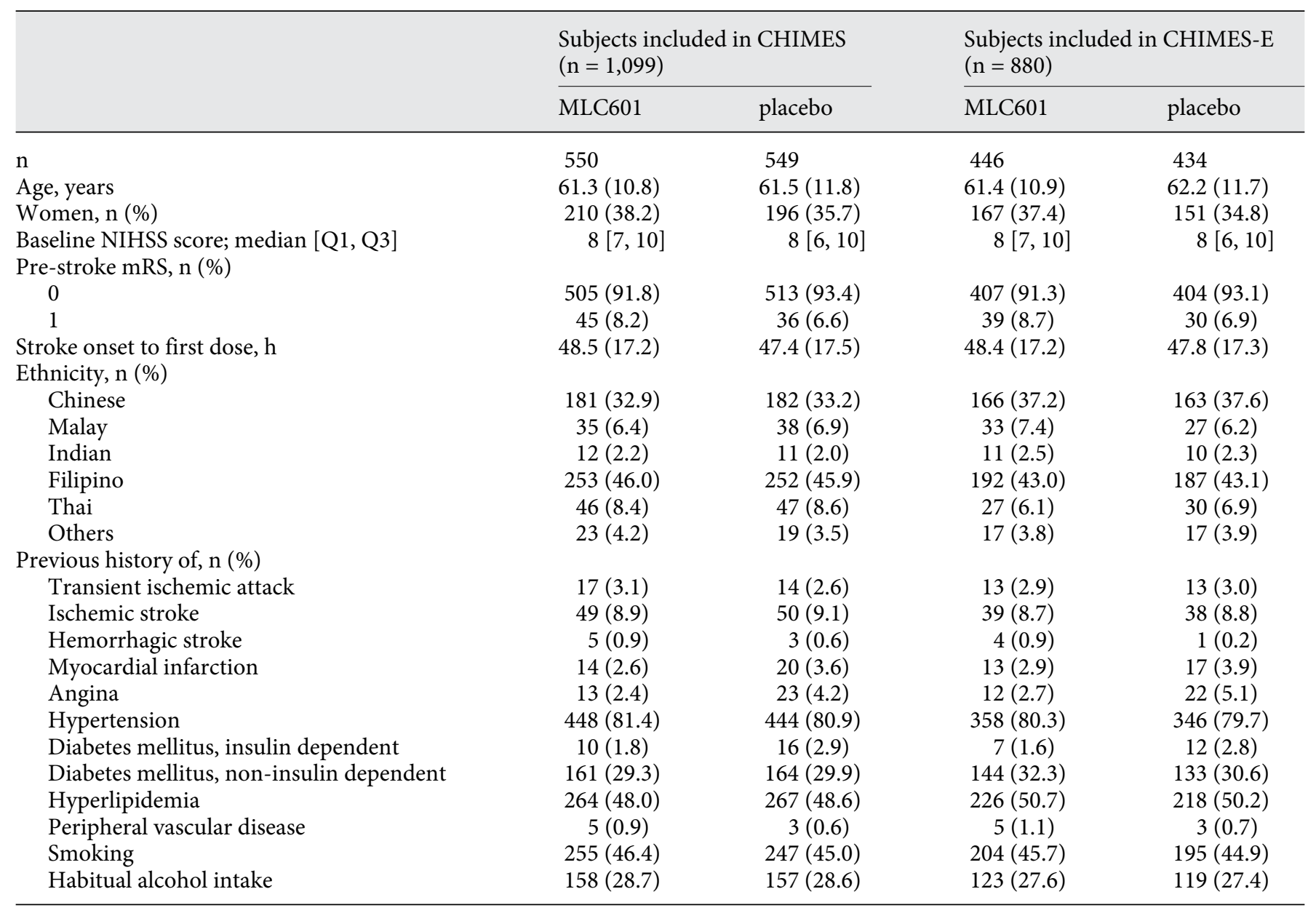

Data are number (\%) or mean (standard deviation). NIHSS = National Institute of Health Stroke Scale; mRS = modified Rankin Scale.

cebo and MLC601 groups was tested using the Mann-Whitney $\mathrm{U}$ test with allowance for ties. Ordinal logistic regression using study groups as the independent variable was performed to provide an estimate of the OR and corresponding 95\% confidence interval (CI) and further adjusted for potentially prognostic factors.

Secondary endpoint measures were functional independence defined on mRS as a score of $\leq 1$ and on BI as a score of $\geq 95$ at months 6, 12, 18 and 24. Outcomes were compared using the Chisquare test or Fisher's exact test. Logistic regression adjusting for potential prognostic factors was performed.

Sensitivity analysis based on the last observation carried forward (LOCF) method by imputing 18-month mRS and per-protocol analyses were carried out and compared to the results of the main analysis. Pre-specified subgroup analyses included age, sex, time from stroke onset, baseline NIHSS score, and presence of cortical signs on baseline NIHSS.

Even though there was no study treatment provided in CHIMES-E, the long-term safety of MLC601 was assessed by the occurrence of any new medical condition, including death and vascular events defined as recurrent stroke or transient ischemic attack, acute coronary event, peripheral vascular disease, pulmonary embolism, and sudden death, over the study period.

\section{Results}

Of the 1,069 potential subjects from the CHIMES Study, 880 subjects were included in CHIMES-E (fig. 1). The CHIMES-E cohort was comparable to the CHIMES cohort [18] as to demographics, stroke severity, stroke onset to treatment time, and risk factor profile (table 1). Month $3 \mathrm{mRS}$ was similar between subjects who were included in CHIMES-E and those who were not (ordinal logistic regression $\mathrm{p}=0.8568$; table 2 ). The CHIMES-E study population had an overall mean age of $61.8 \pm 11.3$ with $318(36 \%)$ women and mean baseline NIHSS of 
Table 2. Comparison of month 3 mRS scores from the CHIMES study of subjects who were subsequently included in CHIMES-E $(\mathrm{n}=880)$ and those who were not $(\mathrm{n}=189)$

\begin{tabular}{|c|c|c|c|c|c|c|}
\hline $\begin{array}{l}\text { Month } 3 \text { mRS in } \\
\text { CHIMES study }\end{array}$ & \multicolumn{3}{|c|}{ Subjects included in CHIMES-E } & \multicolumn{3}{|c|}{ Subjects not included in CHIMES-E } \\
\hline 0 & $131(15.6)$ & $66(15.5)$ & $65(15.8)$ & $24(16.3)$ & $11(16.7)$ & $13(16.0)$ \\
\hline 1 & $264(31.5)$ & $146(34.3)$ & $118(28.6)$ & $49(33.3)$ & $20(30.3)$ & $29(35.8)$ \\
\hline 2 & $194(23.2)$ & $96(22.5)$ & $98(23.8)$ & $30(20.4)$ & $11(16.7)$ & $19(23.5)$ \\
\hline 5 & $8(1.0)$ & $3(0.7)$ & $5(1.2)$ & $1(0.7)$ & $0(0.0)$ & $1(1.2)$ \\
\hline 6 & $27(3.2)$ & $13(3.1)$ & $14(3.4)$ & $0(0.0)$ & $0(0.0)$ & $0(0.0)$ \\
\hline
\end{tabular}

Data are number (\%). mRS = Modified Rankin Scale.

Table 3. Rehabilitation, intake of any traditional Chinese medicine and placement among subjects in CHIMES-E

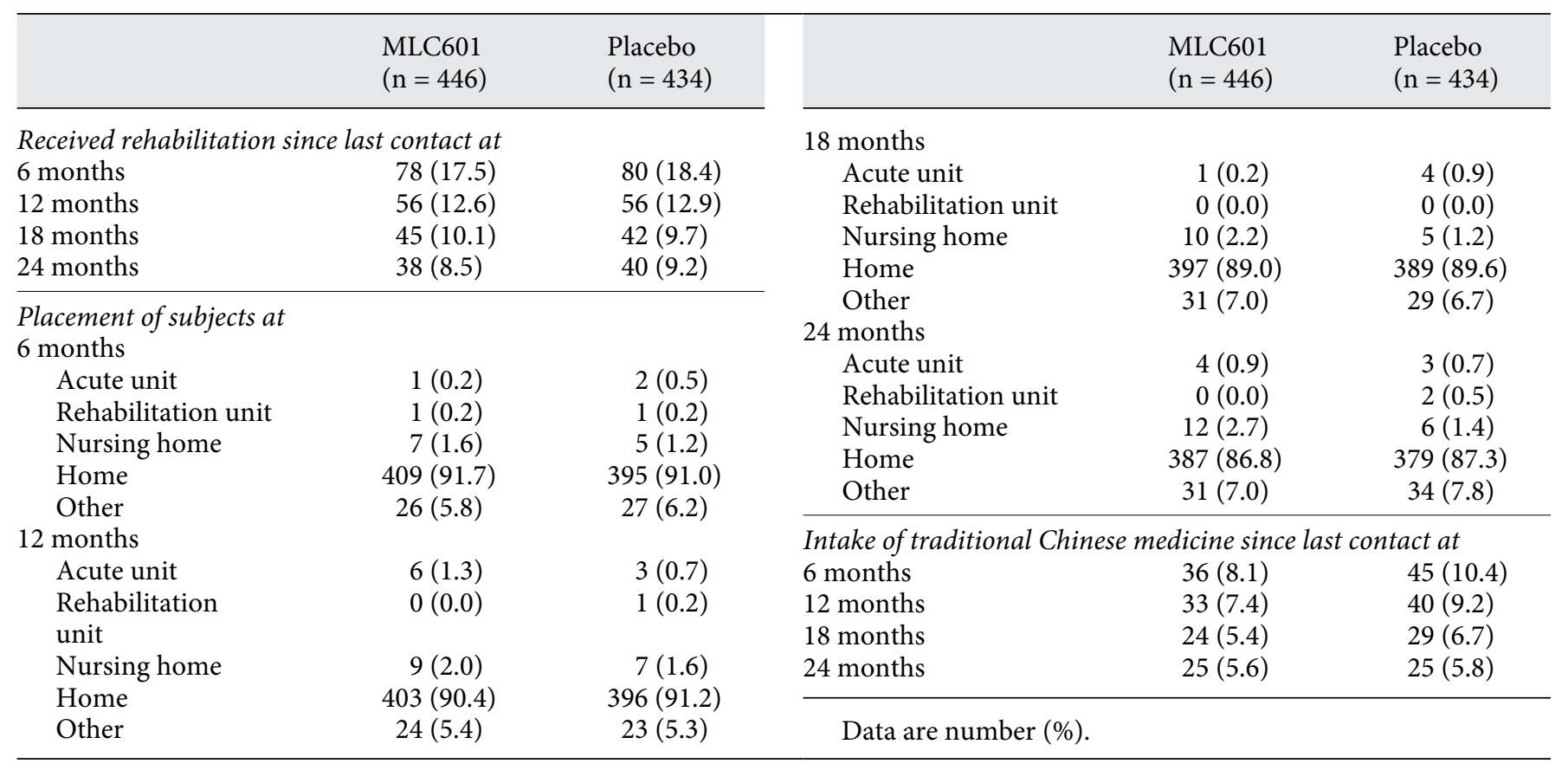

$8.6 \pm 2.5$. The treatment and placebo groups were balanced in baseline characteristics at the time of inclusion in CHIMES. They were likewise similar in terms of subsequent rehabilitation and intake of any TCM over the study period (table 3 ).

Unadjusted OR for the primary end-point for 24-month mRS by ordinal logistic regression was 1.09 (95\% CI 0.86$1.39, \mathrm{p}=0.456)$. Multivariable ordinal logistic regression showed an OR of 1.08 (95\% CI 0.85-1.37, p = 0.543) after adjusting for prognostic factors, that is, age $(\mathrm{p}<0.001)$, sex $(\mathrm{p}=0.005)$, stroke onset to study treatment $(\mathrm{p}=0.331)$, baseline NIHSS $(\mathrm{p}<0.001)$, and pre-stroke mRS $(\mathrm{p}<$ 0.001 ). Analyses using LOCF and per protocol population showed qualitatively similar results (fig. 2).

Adjusted OR for achieving mRS of $\leq 1$ at month 24 was in favor of MLC601 but it did not reach statistical significance. However, MLC601 was significantly associated with increased odds of attaining functional independence 
Fig. 2. Forest plot of outcomes and subgroups by intention-to-treat analyses. LOCF $=$ Last observation carried forward.

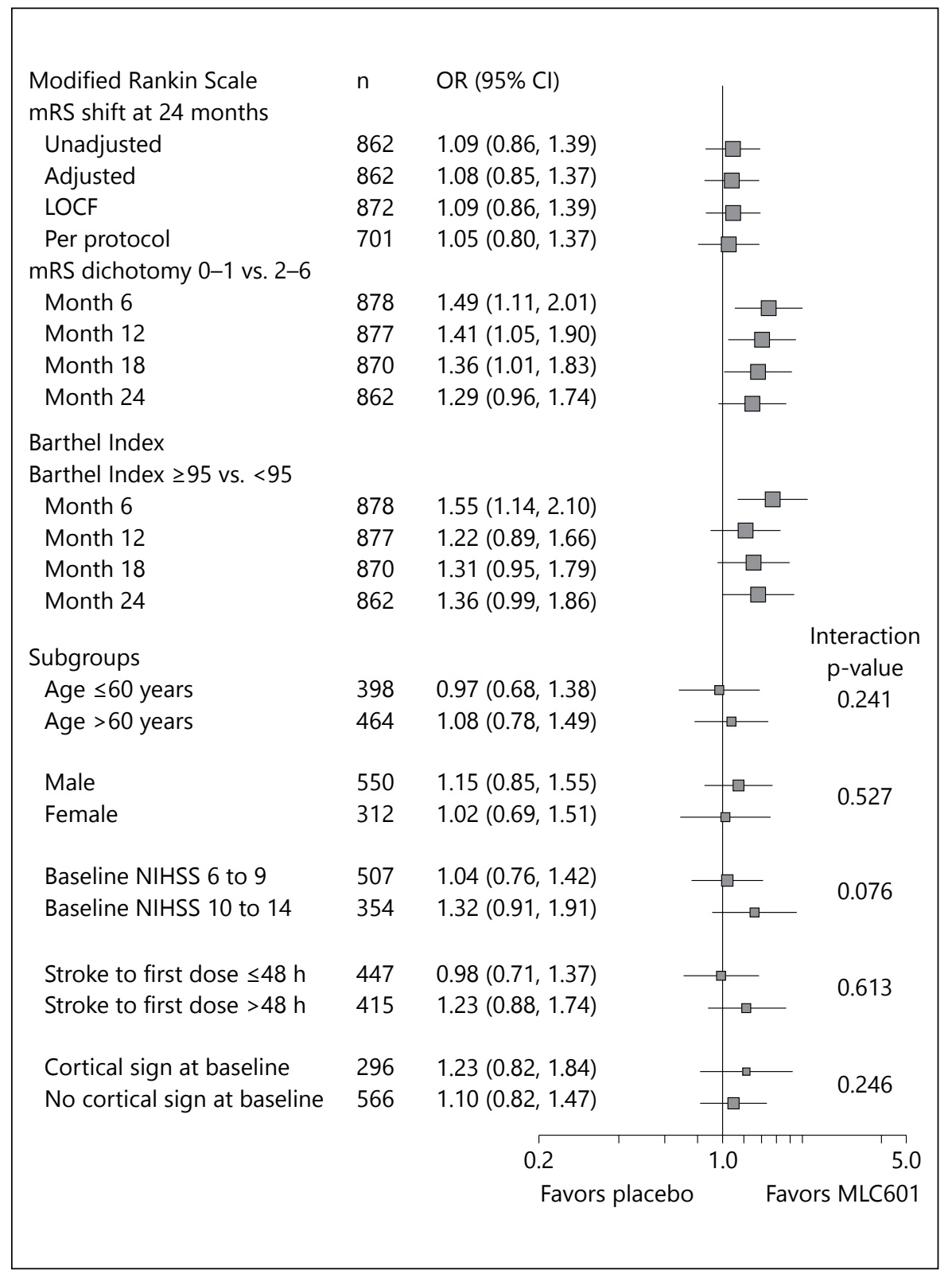

defined as $m R S$ of $\leq 1$ at 6,12 , and 18 months as well as BI of $\geq 95$ at 6 months (fig. 2). Subgroup analyses showed no treatment heterogeneity for the primary outcome. We performed a sensitivity analysis using 3 models: imputing CHIMES month 3 data for subjects with no CHIMES-E data, assuming all subjects with no CHIMES-E data as having the worst outcome, and assuming all subjects with no CHIMES-E data as having the best outcome. As expected, there were variations in statistical significance, but the trajectories of the point estimates over time were all qualitatively similar (table 4).
Long-term safety of a 3-month treatment course of MLC601 was assessed by the reporting of the occurrence of death and medical events over the study period. By month 24, rates of death and occurrence of any vascular event were similar between study groups. Other medical events classified according to organ system are presented in table 5. In particular, there was no difference in the rates of renal or hepatic adverse events. Neoplasm was reported in 4 subjects each for the MLC601-treated (gynecologic 1 , lung 2 , urinary 1 ) and placebo-treated (parathyroid 1 , lung 2 , urinary 1 ) groups. 
Table 4. Sensitivity analysis for mRS dichotomy 0-1 using 3 models: imputing CHIMES month 3 data for subjects with no CHIMES-E data, assuming all subjects with no CHIMES-E data as having the worst outcome, and assuming all subjects with no CHIMES-E data as having the best outcome

\begin{tabular}{llll}
\hline mRS 0-1 & $\begin{array}{l}\text { LOCF from CHIMES } \\
\text { month 3 data }\end{array}$ & $\begin{array}{l}\text { Assuming worst outcome } \\
\text { for missing data }\end{array}$ & $\begin{array}{l}\text { Assuming best } \\
\text { outcome for missing data }\end{array}$ \\
\hline Month 6 & $1.24(0.97-1.58)$ & $1.37(1.07-1.76)$ & $1.25(0.97-1.60)$ \\
Month 12 & $1.20(0.94-1.54)$ & $1.33(1.04-1.70)$ & $1.22(0.95-1.57)$ \\
Month 18 & $1.18(0.92-1.50)$ & $1.29(1.00-1.65)$ & $1.20(0.93-1.54)$ \\
Month 24 & $1.13(0.89-1.45)$ & $1.23(0.96-1.58)$ & $1.16(0.90-1.50)$ \\
\hline
\end{tabular}

mRS = Modified Rankin Scale; LOCF = last observation carried forward.

Table 5. Number of subjects experiencing death and medical events in CHIMES-E

\begin{tabular}{lcc}
\hline & $\begin{array}{c}\text { NeuroAiD } \\
(\mathrm{n}=446)\end{array}$ & $\begin{array}{l}\text { Placebo } \\
(\mathrm{n}=434)\end{array}$ \\
\hline Death & 28 & 29 \\
Vascular event* & 56 & 55 \\
Central nervous system, & & \\
$\quad$ non-vascular & 24 & 19 \\
Cardiac, non-vascular & 5 & 3 \\
Hepatobiliary & 2 & 2 \\
Renal & 10 & 9 \\
Hematologic & 12 & 8 \\
Dermatologic & 2 & 0 \\
Endocrine & 9 & 5 \\
Gastrointestinal & 18 & 16 \\
Gynecologic & 2 & 0 \\
Infection & 23 & 26 \\
Ophthalmologic & 0 & 1 \\
Orthopedic & 7 & 7 \\
Psychiatric & 4 & 1 \\
Pulmonary & 3 & 6 \\
Rheumatologic & 6 & 7 \\
Urinary & 5 & 6 \\
\hline
\end{tabular}

* Recurrent stroke or transient ischemic attack, acute coronary event, pulmonary embolism, peripheral vascular disease, sudden death.

\section{Discussion}

Our study is a planned follow-up of the largest randomized placebo-controlled clinical trial of traditional medicine in ischemic stroke. In this study, an initial 3-month treatment with MLC601 did not demonstrate a statistically significant benefit at 3 months [18] and similarly at 24 months. However, the odds of achieving func- tional independence as defined by an $\mathrm{mRS} \leq 1$ were significantly increased at 6 months and persisted up to 18 months after a stroke. The absolute benefit of achieving an independent functional outcome $(\mathrm{mRS} \leq 1)$ was 80 per 1,000 treated patients at 6 months, 71 per 1,000 at 12 months, 64 per 1,000 at 18 months, and 53 per 1,000 at 24 months.

Precedents in stroke trials of treatments that showed 'delayed' statistical benefit beyond the period at which the effect was expected have been reported. Intravenous recombinant tissue plasminogen activator, although only administered once during the hyperacute phase of stroke as a revascularization procedure, failed to reach statistical significance on NIHSS at $24 \mathrm{~h}$, but improved functional outcomes at 3 months [24]. MLC601 has been shown in tissue and animal models to enhance the self-reparative processes in the brain after an injury in addition to its neuroprotective effects $[4,5]$. Such processes take time and thus it is plausible that effects may not be apparent very soon after the initiation of treatment. Benefits may accrue and appear only some time after the treatment has been started. In an earlier pilot study in which stroke patients were treated with MLC601 for only 1 month, improvement in motor recovery appeared at 2 months, although we have to admit that the sample size for that study was small [10].

Apart from efficacy, CHIMES-E provided further safety data on MLC601 even when combined with other stroke treatments used in the clinical setting, showing no increase in the rates of delayed adverse event that may occur even after treatment was discontinued, such as malignancies and chronic effects on renal or hepatic function. Such long-term efficacy and safety information are not commonly available in many stroke trials. While the use of natural products such as MLC601 may have greater acceptance in cultures already using herbal remedies, such 
as in Asia where there is a high stroke burden, the performance of this study according to international standards also have an impact on its use in other parts of the world.

Our study has some important implications for future stroke trials. It is well known that stroke patients spontaneously recover to a great extent during the first three months after a stroke, especially among the less severe cases [25]. Demonstrating effects on recovery during this period may be more difficult than at a later time when spontaneous improvement is less likely to confound the study. Recently, it has also been shown that transition from independence in activities of daily living to dependency between 3 and 12 months after a stroke is not insignificant [26]. A follow-up period of 3 months, as is the case in many acute stroke trials, may be of insufficient duration to demonstrate a treatment effect and may require strict patient selection as we have shown in our cohort $[27,28]$. Longer assessments after the initial shortcourse therapy may help in further evaluating stroke treatments, such as those using neuroprotectants, previously thought to be ineffective. The transition between brain injury and repair is highly regulated and complex such that many therapeutic targets have temporal profiles $[29,30]$. Treatment candidates should consider this transition by carefully defining the optimal time for administration as well as the time of assessment of effects.

Moreover, our findings emphasize the importance of using the most suitable statistical model for analyzing trial cohorts based on their predicted behavior in the study [31]. The functional gains seen in our study appear to be limited to a higher proportion of subjects attaining full independence as measured by $\mathrm{mRS}$ assuming the efficacy of the investigational compound. This is still clinically relevant to stroke patients and caregivers, with more subjects returning to normal living and less caregiver burden. The mRS shift analysis did not show significant differences in outcome between treatment groups, although the point estimates were in favor of MLC601 and could conceivably reach statistical significance with a much larger sample size. The inability to detect statistical significance on ordinal analysis was likely due to not having the expected effect size across the range of mRS and not taking into account possible misclassifications of outcomes in a categorical scale. Such errors have been shown to severely underestimate the sample size calculation [32,33]. While using the full range of mRS is attractive, it may be fraught with uncertainty in assessments, making dichotomization more appealing as it leads to lower error rates [33].

As previously reported, patients included in CHIMES were relatively of milder severity many of whom have re- covered well by three months even in the placebo group [18]. Having few patients in the more severe spectrum of mRS may have affected the power to detect significant 'shifts' across scores between treatment groups as previously alluded to by others [31]. On the other hand, the benefits in our cohort clustered at a single transition make dichotomy analysis more advantageous in demonstrating a difference in achieving near complete to complete recovery.

We previously hypothesized that a longer duration of treatment and follow-up of patients may improve the sensitivity of detecting the effects on long-term recovery [18]. We have also previously shown a reduction in early vascular events with MLC601 treatment for 3 months [19]. In CHIMES-E, we noted consistently favorable treatment effect for all assessment time points but the largest effect was seen at 6 months with a gradual decline at 24 months; however, no difference in rates of vascular events was observed. This suggests a wearing off of effect of the initial 3-month treatment course, both for functional recovery and even more so for secondary prevention, and suggests a need for longer treatment duration or continuous treatment.

There are limitations and possibly unrecognized confounders that could be potential sources of type I error in our study. We were able to achieve only $80 \%$ follow-up of the original subjects included in CHIMES. Nonetheless, this was more than expected in the power calculation and is no worse than other long-term cardiovascular studies, particularly when study treatment was no longer continued [34-39]. Furthermore, we investigated if attrition bias existed in our cohort. The baseline characteristics and month $3 \mathrm{mRS}$ were comparable between subjects with and those without CHIMES-E data, while sensitivity analyses showed the same relationship between treatment and outcomes for all time points. Another possible limitation is that we performed telephone rather than inperson assessments. Face-to-face mRS assessment have been reported to be prone to bias and inter-rater variability, which may be improved by using structured interviews [40-42]. Telephone assessments of mRS and BI likely suffer from the same shortcomings, although some have shown them to be as reliable as face-to-face evaluations [43-46]. On the other hand, telephone-based assessments improve subject retention and minimize missing data in longitudinal studies [47]. Trial-related training for assessing mRS, BI, and NIHSS in the CHIMES-E study was not performed. It is possible that assessment or ascertainment bias may have occurred in our study, although investigators were experienced stroke trialists. 
The main strength of CHIMES-E was that it was based on a well-conducted multicenter acute stroke trial with a large sample size and performed in a blinded, placebocontrolled manner, with a long-term follow-up. The endpoints were robust and were used in most stroke trials. The results were consistent at various time points and seen on 2 indices, that is, $\mathrm{mRS}$ and $\mathrm{BI}$.

In conclusion, while the benefits of a 3-month treatment with MLC601 did not reach statistical significance for the primary endpoint at 2 years, the odds of achieving functional independence defined as $\mathrm{mRS} \leq 1$ at 6 months was significantly increased and persisted up to 18 months after a stroke. A longer duration of treatment and followup beyond the conventional 3-month study period should be considered in stroke trials of agents with putative neuroprotective and restorative effects.

\section{Sources of Funding}

The CHIMES-E study was supported by the CHIMES Society, a nonprofit organization, and grants were received by CLHC from the National Medical Research Council of Singapore (NMRC/ 1288/2011 and NMRC/1096/2006).

\section{CHIMES-E Study Investigators}

Singapore - Narayanaswamy Venketasubramanian, Sherry H. Young, Marlie Jane Mamauag, San San Tay, Shrikant Pande, Thirugnanam Umapathi, Rajinder Singh, Hui Meng Chang, Deidre Anne de Silva, Bernard P.L. Chan, Vijay Sharma, Teoh Hock Luen. Philippines - Jose C. Navarro, Herminigildo H. Gan, Annabelle Y. Lao, Alejandro C. Baroque II, Johnny Lokin, John Harold B. Hiyadan, Ma. Socorro Sarfati, Randolph John Fangonillo, Neil Ambasing, Carlos Chua, Ma. Cristina San Jose, Joel Advincula, Eli John Berame. Thailand - Niphon Poungvarin, Sombat Muengtaweepongsa, Songkram Chotickanuchit, Nijasri Suwanwela. Sri Lanka - H. Asita de Silva, Udaya Ranawake, Nirmala Wijekoon. Hong Kong - K.S. Lawrence Wong. Malaysia - Gaik Bee Eow.

\section{Disclosures}

The authors received funding for the trial and accommodation and transportation support for meetings from the CHIMES Society. Moleac (Singapore) provided grants to the CHIMES Society of which the society had sole discretion on use. J.C.N. has minor shares in $\mathrm{E}^{*}$ Chimes, the Philippine distributor of NeuroAiD ${ }^{\mathrm{TM}}$. Other than CHIMES funding for the trial, the other authors and investigators do not have any conflict of interest to declare.

\section{References}

$\checkmark 1$ European Stroke Organisation (ESO) Executive Committee; ESO Writing Committee: Guidelines for management of ischaemic stroke and transient ischaemic attack 2008. Cerebrovasc Dis 2008;25:457-507.

2 Ginsberg MD: Current status of neuroprotection for cerebral ischemia: synoptic overview. Stroke 2009;40(3 suppl):S111-S114.

-3 Pandian JD, Liu M, Misbach J, Venketasubramanian N: Alternative therapies for stroke treatment in Asia. Int J Stroke 2011;6:541543.

4 Heurteaux C, Gandin C, Borsotto M, Widmann C, Brau F, Lhuillier M, Onteniente B, Lazdunski M: Neuroprotective and neuroproliferative activities of NeuroAid (MLC601, MLC901), a Chinese medicine, in vitro and in vivo. Neuropharmacology 2010;58:9871001.

-5 Quintard H, Borsotto M, Veyssiere J, Gandin C, Labbal F, Widmann C, Lazdunski M, Heurteaux C: MLC901, a traditional Chinese medicine protects the brain against global ischemia. Neuropharmacology 2011;61:622631.

6 Moha Ou Maati H, Borsotto M, Chatelain F, Widmann C, Lazdunski M, Heurteaux C: Activation of ATP-sensitive potassium channels as an element of the neuroprotective effects of the traditional Chinese medicine MLC901 against oxygen glucose deprivation. Neuropharmacology 2012;63:692-700.

7 Siddiqui FJ, Venketasubramanian N, Chan ES, Chen C: Efficacy and safety of MLC601 $\left(\right.$ NeuroAiD ${ }^{\circledR}$ ), a traditional Chinese medicine, in poststroke recovery: a systematic review. Cerebrovasc Dis 2013;35(suppl 1):8-17.

$>8$ Chen C, Venketasubramanian N, Gan RN, Lambert C, Picard D, Chan BP, Chan E, Bousser MG, Xuemin S: Danqi Piantang Jiaonang (DJ), a traditional Chinese medicine, in poststroke recovery. Stroke 2009;40:859-863.

$\checkmark 9$ Harandi AA, Abolfazli R, Hatemian A, Ghragozlee K, Ghaffar-Pour M, Karimi M, Shahbegi S, Pakdaman H, Tabasi M, Tabatabae AL, Nourian A: Safety and efficacy of MLC601 in Iranian patients after stroke: a double-blind, placebo-controlled clinical trial. Stroke Res Treat 2011;2011:721613.

10 Kong KH, Wee SK, Ng CY, Chua K, Chan KF, Venketasubramanian N, Chen C: A doubleblind, placebo-controlled, randomized phase II pilot study to investigate the potential efficacy of the traditional Chinese medicine Neuroaid (MLC 601) in enhancing recovery after stroke (TIERS). Cerebrovasc Dis 2009;28: 514-521.

11 Bavarsad Shahripour R, Shamsaei G, Pakdaman $H$, Majdinasab N, Nejad EM, Sajedi SA, Norouzi M, Hemmati A, Manouchehri
RH, Shiravi A: The effect of NeuroAiD ${ }^{\mathrm{TM}}$ (MLC601) on cerebral blood flow velocity in subjects' post brain infarct in the middle cerebral artery territory. Eur J Intern Med 2011; 22:509-513.

12 Ghandehari K, Mood ZI, Ebrahimzadeh S, Picard D, Zhang Y: NeuroAid (MLC601) versus piracetam in the recovery of post-infarct homonymous hemianopsia. Neural Regen Res 2011;6:418-422.

$\$ 13$ Navarro JC, Molina MC, Baroque Ii AC, Lokin JK: The use of NeuroAiD (MLC601) in postischemic stroke patients. Rehabil Res Pract 2012;2012:506387.

14 Siow CH: Neuroaid in stroke recovery. Eur Neurol 2008;60:264-266.

15 Young SH, Zhao Y, Koh A, Singh R, Chan BP, Chang HM, Venketasubramanian N, Chen C; CHIMES Investigators: Safety profile of MLC601 (Neuroaid) in acute ischemic stroke patients: a Singaporean substudy of the Chinese medicine Neuroaid efficacy on stroke recovery study. Cerebrovasc Dis 2010;30:1-6.

-16 Gan R, Lambert C, Lianting J, Chan ES, Venketasubramanian N, Chen C, Chan BP, Samama MM, Bousser MG: Danqi Piantan Jiaonang does not modify hemostasis, hematology, and biochemistry in normal subjects and stroke patients. Cerebrovasc Dis 2008;25: 450-456. 
17 Venketasubramanian N, Chen CL, Gan RN, Chan BP, Chang HM, Tan SB, Picard D, Navarro JC, Baroque AC 2nd, Poungvarin N, Donnan GA, Bousser MG; CHIMES Investigators: A double-blind, placebo-controlled, randomized, multicenter study to investigate CHInese Medicine Neuroaid Efficacy on Stroke recovery (CHIMES Study). Int J Stroke 2009;4:54-60.

18 Chen CL, Young SH, Gan HH, Singh R, Lao $\mathrm{AY}$, Baroque AC 2nd, Chang HM, Hiyadan $\mathrm{JH}$, Chua CL, Advincula JM, Muengtaweepongsa S, Chan BP, de Silva HA, Towanabut S, Suwanwela NC, Poungvarin N, Chankrachang S, Wong KS, Eow GB, Navarro JC, Venketasubramanian N, Lee CF, Bousser MG; CHIMES Study Investigators: Chinese medicine Neuroaid efficacy on stroke recovery: a double-blind, placebo-controlled, randomized study. Stroke 2013;44:2093-2100.

$\checkmark 19$ Chen CL, Venketasubramanian N, Lee CF, Wong KS, Bousser MG; CHIMES Study Investigators: Effects of MLC601 on early vascular events in patients after stroke: the CHIMES study. Stroke 2013;44:3580-3583.

20 Venketasubramanian N, Young S, Tay SS, Chang HM, Umapathi T, Chan B, de Silva A, Wong L, Navarro J, Zhao YD, Tan SB, Chen C: Chinese medicine NeuroAiD efficacy stroke recovery-extension study (CHIMES-E study): an observational multicenter study to investigate the longer-term efficacy of NeuroAiD in stroke recovery. Cerebrovasc Dis 2013;35(suppl 1):18-22.

21 Appelros P, Nydevik I, Viitanen M: Poor outcome after first-ever stroke: predictors for death, dependency, and recurrent stroke within the first year. Stroke 2003;34:122-126.

-22 Hankey GJ: Long-term outcome after ischaemic stroke/transient ischaemic attack. Cerebrovasc Dis 2003;16(suppl 1):14-19.

23 Fransen M, Anderson C, Chalmers J, Chapman N, Davis S, MacMahon S, Neal B, Sega R, Terent A, Tzourio C, Woodward M; PROGRESS: Effects of a perindopril-based blood pressure-lowering regimen on disability and dependency in 6105 patients with cerebrovascular disease: a randomized controlled trial. Stroke 2003;34:2333-2338.

24 Tissue plasminogen activator for acute ischemic stroke. The national institute of neurological disorders and stroke rt-PA stroke study group. N Engl J Med 1995;333:15811587.

25 Duncan PW, Goldstein LB, Matchar D, Divine GW, Feussner J: Measurement of motor recovery after stroke. Outcome assessment and sample size requirements. Stroke 1992; 23:1084-1089.

26 Ullberg T, Zia E, Petersson J, Norrving B: Changes in functional outcome over the first year after stroke: an observational study from the Swedish stroke register. Stroke 2015;46: 389-394.

-27 Navarro JC, Gan HH, Lao AY, Baroque AC 2nd, Hiyadan JH, Chua CL, San Jose MC, Advincula JM, Lee CF, Bousser MG, Chen CL; CHIMES Study Investigators: Baseline characteristics and treatment response of patients from the Philippines in the CHIMES study. Int J Stroke 2014;9(suppl A100):102-105.

28 Chankrachang S, Navarro JC, De Silva DA, Towanabut S, Chua CL, Lee CF, Venketasubramanian N, Wong KS, Bousser MG, Chen CL; CHIMES Study Investigators: Prognostic factors and treatment effect in the CHIMES study. J Stroke Cerebrovasc Dis 2015;24:823827.

29 Lo EH: A new penumbra: transitioning from injury into repair after stroke. Nat Med 2008; 14:497-500.

30 Dirnagl U, Iadecola C, Moskowitz MA: Pathobiology of ischaemic stroke: an integrated view. Trends Neurosci 1999;22:391-397.

-31 Saver JL, Gornbein J: Treatment effects for which shift or binary analyses are advantageous in acute stroke trials. Neurology 2009; 72:1310-1315.

32 Whitehead J: Sample size calculations for ordered categorical data. Stat Med 1993;12: 2257-2271.

33 Mandava P, Krumpelman CS, Shah JN, White DL, Kent TA: Quantification of errors in ordinal outcome scales using shannon entropy: effect on sample size calculations. PLoS One 2013;8:e67754.

-34 Wolf SL, Winstein CJ, Miller JP, Taub E, Uswatte G, Morris D, Giuliani C, Light KE, Nichols-Larsen D; EXCITE Investigators: Effect of constraint-induced movement therapy on upper extremity function 3 to 9 months after stroke: the EXCITE randomized clinical trial. JAMA 2006;296:2095-2104.

35 Blanton S, Morris DM, Prettyman MG, McCulloch K, Redmond S, Light KE, Wolf SL: Lessons learned in participant recruitment and retention: the EXCITE trial. Phys Ther 2006;86:1520-1533.

- 36 Gurm HS, Yadav JS, Fayad P, Katzen BT, Mishkel GJ, Bajwa TK, Ansel G, Strickman NE, Wang H, Cohen SA, Massaro JM, Cutlip DE; SAPPHIRE Investigators: Long-term re- sults of carotid stenting versus endarterectomy in high-risk patients. N Engl J Med 2008; 358:1572-1579.

- 37 Bhaskar R, Reitman D, Sacks HS, Smith H Jr, Chalmers TC: Loss of patients in clinical trials that measure long-term survival following myocardial infarction. Control Clin Trials 1986;7:134-148.

38 Glader EL, Stegmayr B, Asplund K: Poststroke fatigue: a 2-year follow-up study of stroke patients in Sweden. Stroke 2002;33: 1327-1333.

39 Cofield SS, Conwit R, Barsan W, Quinn J: Recruitment and retention of patients into emergency medicine clinical trials. Acad Emerg Med 2010;17:1104-1112.

40 van Swieten JC, Koudstaal PJ, Visser MC, Schouten HJ, van Gijn J: Interobserver agreement for the assessment of handicap in stroke patients. Stroke 1988;19:604-607.

41 Wilson JT, Hareendran A, Grant M, Baird T, Schulz UG, Muir KW, Bone I: Improving the assessment of outcomes in stroke: use of a structured interview to assign grades on the modified Rankin Scale. Stroke 2002;33:22432246.

42 Wilson JT, Hareendran A, Hendry A, Potter J, Bone I, Muir KW: Reliability of the modified Rankin Scale across multiple raters: benefits of a structured interview. Stroke 2005;36: 777-781.

43 Janssen PM, Visser NA, Dorhout Mees SM, Klijn CJ, Algra A, Rinkel GJ: Comparison of telephone and face-to-face assessment of the modified Rankin Scale. Cerebrovasc Dis 2010; 29:137-139.

44 Savio K, Pietra GL, Oddone E, Reggiani M, Leone MA: Reliability of the modified Rankin Scale applied by telephone. Neurol Int 2013; 5:e2.

45 Della Pietra GL, Savio K, Oddone E, Reggiani $\mathrm{M}$, Monaco F, Leone MA: Validity and reliability of the Barthel index administered by telephone. Stroke 2011;42:2077-2079.

46 Shinar D, Gross CR, Bronstein KS, LicataGehr EE, Eden DT, Cabrera AR, Fishman IG, Roth AA, Barwick JA, Kunitz SC: Reliability of the activities of daily living scale and its use in telephone interview. Arch Phys Med Rehabil 1987;68:723-728.

47 Claassen C, Kurian B, Trivedi MH, Grannemann BD, Tuli E, Pipes R, Preston AM, Flood A: Telephone-based assessments to minimize missing data in longitudinal depression trials: a project IMPACTS study report. Contemp Clin Trials 2009;30:13-19. 